\title{
Review on Cyanide Poisoning in Ruminants
}

\author{
Ufaysa Gensa \\ Jimma University College of Agriculture and Veterinary Medicine, School of Veterinary Medicine. \\ P.O. box 307, Jimma, Oromia, Ethiopia
}

\begin{abstract}
SUMMARY
Cyanide is one of the most potent and rapidly acting inorganic poisons and it can cause toxicity in animals, principally in ruminants. Although cyanides are released to environment in various forms, the natural source of cyanide ion from plants that contain enough cyanogenic glycosides are the most important cause of hydrogen cyanide poisoning in ruminants. The objective of this paper is to review available information on cyanide poisoning in ruminants and to highlight its diagnosis, prevention and treatment options. The cyanide toxicity in ruminants is affected primarily by lethal dose, plant, environment, and animal factors. Ruminants are more susceptible to prussic acid poisoning than other domestic animals, due to more efficient hydrolysis of the cyanogenic glycosides in the rumen. The mechanism of cyanide intoxication involves, inhibition of oxidative metabolism and oxygen utilization of cells, by binding with heme form of cytochrome a3 (cytochrome oxidase) which is last enzyme in the respiratory electron transport chain. As result of this process, affected ruminant's shows signs of acute cyanide intoxication mainly the reflection of cellular hypoxia including hyperventilation, decreased blood pressure, hypoxemia-induced convulsions, coma, shock, respiratory failure and death within few minutes to hours. Nevertheless, in most cases the affected animals die due to rapidly acting nature of the toxin; ruminants can be treated immediately with specific antidote. Combination of sodium nitrite and sodium thiosulfate is commonly dosed orally as antidote of choice. The use of appropriate prevention measures can reduce the risk from potentially toxic forages. The rapid administration of sodium thiosulphate alone or in combination with sodium nitrite intravenously (IV) to early noticed should be done to reduce losses of livestock.
\end{abstract} Keywords: Cyanide, ruminants, toxicity, hydrogen cyanide;

DOI: $10.7176 / \mathrm{JBAH} / 9-6-01$

Publication date:March $31^{\text {st }} 2019$

\section{INTRODUCTION}

The term "cyanides" is used to describe compounds which contain in their structure the $-\mathrm{C} \equiv \mathrm{N}$ group. In the environment, cyanides can be found in many different forms (Kuyucak and Akcil, 2013). Cyanide, hydrocyanic acid, hydrogen cyanide $(\mathrm{HCN})$ and prussic acid are all terms relating to the same toxic principle (Gupta, 2012). Hydrogen cyanide (HCN) was isolated from blue dye (Prussian blue) for the first time and because of its acidic nature it's also known as "prussic acid" (Clarke et al., 1981). It also exists in various forms including gaseous $\mathrm{HCN}$, water soluble potassium cyanide and sodium cyanide, poorly water soluble mercury, copper, gold and silver cyanide salts (Patel et al., 2014).

Hydrogen cyanide (HCN) is a colorless or pale blue liquid or gas with a faint bitter almond-like odor, while sodium cyanide $(\mathrm{NaCN})$ and potassium cyanide $(\mathrm{KCN})$ are white crystalline powders (Newhouse and Chiu, 2016). According to ATSDR (2006) repot, cyanide originates primarily from anthropogenic sources in the environment, but cyanide is also released from biomass burning, volcanoes, and natural biogenic processes from higher plants, bacteria, and fungi. Among different inorganic poisoning studied till to date, cyanide is one of the most potent inorganic poison of mammals (Patel et al., 2014).

The plants, the most important source of cyanide toxicity in animals, which contains hydrocyanic acid $(\mathrm{HCN})$ either free or inform of cyanogenic glycosides are called as cyanogenetic plants (Gark, 2004). There are various forms of cyanogenic compounds that release hydrogen cyanide upon breakdown. The cyanogenic compound is present mainly as glycoside in more than 2650 plant species. Apricot kernel, peach kernel, cassava, almond, bamboo shoot, sorghum, Japanese apricot, flaxseed among others have been consumed by human worldwide either as food or as herbal medicine (Francisco and Pinotti, 2000; Haque and Bradbury, 2002).

Published paper indicated that the most common source of cyanogenic plant poisoning in India, is feeding of immature sorghum i.e. young shoots of Sorghum vulgare and Sorghum sudanense to livestock or accidental ingestion of pods of Acacia leucocephala by sheep and goats (Vadlamudi, 2000). The glycoside itself is nontoxic, which owes its toxicity to cyanide after hydrolysis (Patel et al., 2014). Cassava is one of livestock feed, and regularly fed to sheep andgoats on small-scale subsistence farms in Africa (Smith, 1992). Cassava tuber contains cyanogenic glycosides, known as linamarin and lotaustralin that could cause toxicity. As a consequence, the animals are exposed to low but constant amounts of cyanide for prolonged periods (Tewe, 1992).

It is reported that, the amount of cyanogenic glycosides in plants varies with plant species and environmental effects (Vickery et al., 1987). Environmental conditions that damage relevant plant species, reduce protein synthesis, enhance the conversion of nitrate to amino acids in the presence of reduced protein 
synthesis, and/or inhibit $\beta$-cyanoalanine synthase potentially increase the risk of cyanogenesis (Rhian, 2012). These cyanogenic compounds are in epidermal cells (outer tissue) of the plant, while the enzymes that enable cyanide production are in the mesophyll cells (leaf tissue) (Charlie and Greg, 2012).

Cattle and sheep, both being ruminants, are known to be subject to poisoning by cyanogenetic glucosides. The rumen of these animals is neither strongly acid nor alkaline, and it contains a large flora of micro-organisms and considerable quantities of enzymes. An excellent medium is thus provided for the hydrolysis of the glucoside with the liberation of the toxic agent--hydrocyanic acid (Vough, 1978). As ruminants consume plant materials containing cyanogenic glycosides, hydrogen cyanide is liberated in the rumen, rapidly absorbed into the bloodstream and prevents hemoglobin from releasing its oxygen to the tissues (Arnold et al., 2014).

In current trend for earning more profit, farmers are trying to cultivate more crops throughout year, so they may cut the forage in immature stage, which is the main source of cyanide toxicity (Patel et al., 2014). Rapid intake of plant equivalent to about $4 \mathrm{mg} \mathrm{HCN} / \mathrm{kg}$ of body weight is considered to be lethal amount of plant material (Booth and McDoland, 1982). The toxic effects and lethality associated with acute exposure to CN- in humans and animals are generally similar (Newhouse and Chiu, 2016). Animals, including ruminants will commonly be found dead since clinical signs last only a few minutes after ingestion (John and Frederick, 1980).

According to Arnold et al. (2014) the most important diagnosis of cyanide poisoning is to identify plants in the area accessible to the animals and determine if they are likely to contain cyanogenic glycosides. Treatment is often too late, and most cases result in death but some early noticed cases can be treated. However, sodium nitrite and sodium thiosulfate should be rapidly administered intravenously to affected ruminants (Gracia and Shepherd, 2004). Rumenotomy is another treatment option; patient's rumen content should be removed and replaced with contents from a healthy animal (Akgül, 2013).

Avoiding hungry cattle and sheep access to toxic plants, especially cultivated Sorghum spp. when they are chronically drought-stressed, immature, wilted, frostbitten, or growing rapidly after a stage of retarded growth is effective means of control (Radostits et al., 2007). Most of the information on cyanide poisoning in ruminants are lacking in Africa including our country, Ethiopia. However, the continuing increase in cultivation of crops and application of herbicide by farmers and wide spread availability of cyanide in the environment as well as increased susceptibility of ruminants to cyanide poisoning necessitates understanding of its pathophysiology and possible managements of toxicity in ruminants. Currently there is no available review made on cyanide poisoning in ruminants in our campus and our country as whole and this review was intended to fill that gap.

The objective of this seminar paper is:

$>$ To review available information on cyanide poisoning in ruminants: its diagnosis, treatment, and prevention options.

\section{LITRETURE REVIEW}

\subsection{Cause}

Animals are more frequently exposed to cyanide through ingestion of plants containing cyanogenic glycosides (Nobrega et al., 2006). The primary cause of cyanide poisoning in ruminants is the ingestion of plants containing cyanide-producing compounds called cyanogenic glycosides (Arnold et al., 2014). At least 55 cyanogenic glycosides are known to occur in plants, many being synthesized from amino acids as part of normal plant metabolism (Knight and Walter, 2002). However, Amygdalin, Prunacin, Linamaryn, Lotaustralyn, Dhurryn, Taxiphylyn, Vicianyn, Proteacynve and Gynocardyn have been detected as most common glycosides in cyanogenic plants (Gracia, 2004).

The content of cyanogenetic glucosides in these plants varies widely between seasons and between different parts of the plant, with young, growing leaf usually having the greatest concentration (Radostits et al., 2007). Crushing or mastication of potentially cyanogenic plants is important in development of the acute toxidrome, because this releases cyanogenic glycosides from plant cell vacuoles and exposes them to catabolism by $\beta$ glucosidase and hydroxynitrilelyase present in the plant cell cytosol. Generally, plant cyanogenesis in response to environmental stressors is an important part of the etiology and risk of acute cyanogenic glycoside poisoning (Rhian, 2012). 
Table 1: Some of plants with enough cyanogenic potential.

Juncus spp., e.g. J. cffusus

Triglochin spp., e.g. T. maritime

\begin{tabular}{ll}
\hline Manihot esculenta, & Vicia sativa, \\
Triraphis mollis, & Leptopus decaisnei,
\end{tabular}

$\begin{array}{ll}\text { Lotus spp., e.g. L. australis, } & \text { Zea mays, } \\ \text { Linum spp., e.g. L. usitassimum, } & \text { Malus spp., e.g. M. sylvestris, }\end{array}$

$\begin{array}{ll}\text { Macadamia spp., e.g. M. integrifolia, } & \text { Drosera spp. } \\ \text { Sorghum spp., e.g. S. halepense, } & \text { Stillingia treculeana, }\end{array}$

$\begin{array}{ll}\text { Suckleya suckleyana, } & \text { Ximenia americana, } \\ \text { Xylomelum spp, } & \text { Phaseolus cuneatus, - }\end{array}$

Source: (Radostits et al., 2007).

\subsection{Epidemiology}

\subsubsection{Occurrence}

Cyanide is present in many industrial and municipal waste waters. The sources of environmental pollution are, among other mines, metallurgical plants and exhaust gas from vehicles. Cyanide ions get into the environment mainly from waste water. These compounds can also enter the environment as a result of fires at industrial workshops and houses as well as from tobacco smoke (Kuyucak and Akcil, 2013). Cyanide ions are generated naturally during biogenic processes of higher plant, bacteria and fungi (Mudder and Botz, 2000).

Furthermore, hydrocyanic acid poisoning occurs in most countries because of the common occurrence of plants containing toxic quantities of cyanogenetic glycosides (Radostits et al., 2007). The principal source of cyanide poisoning to ruminants are plants, in which cyanides are usually bound to sugar molecules in the form of cyanogenic glycosides and defend the plant against herbivores. Cassava roots (also called manioc), an important potato-like food grown in tropical countries (and the base from which tapioca is made), also contain cyanogenic glycosides (Vetter, 2000).

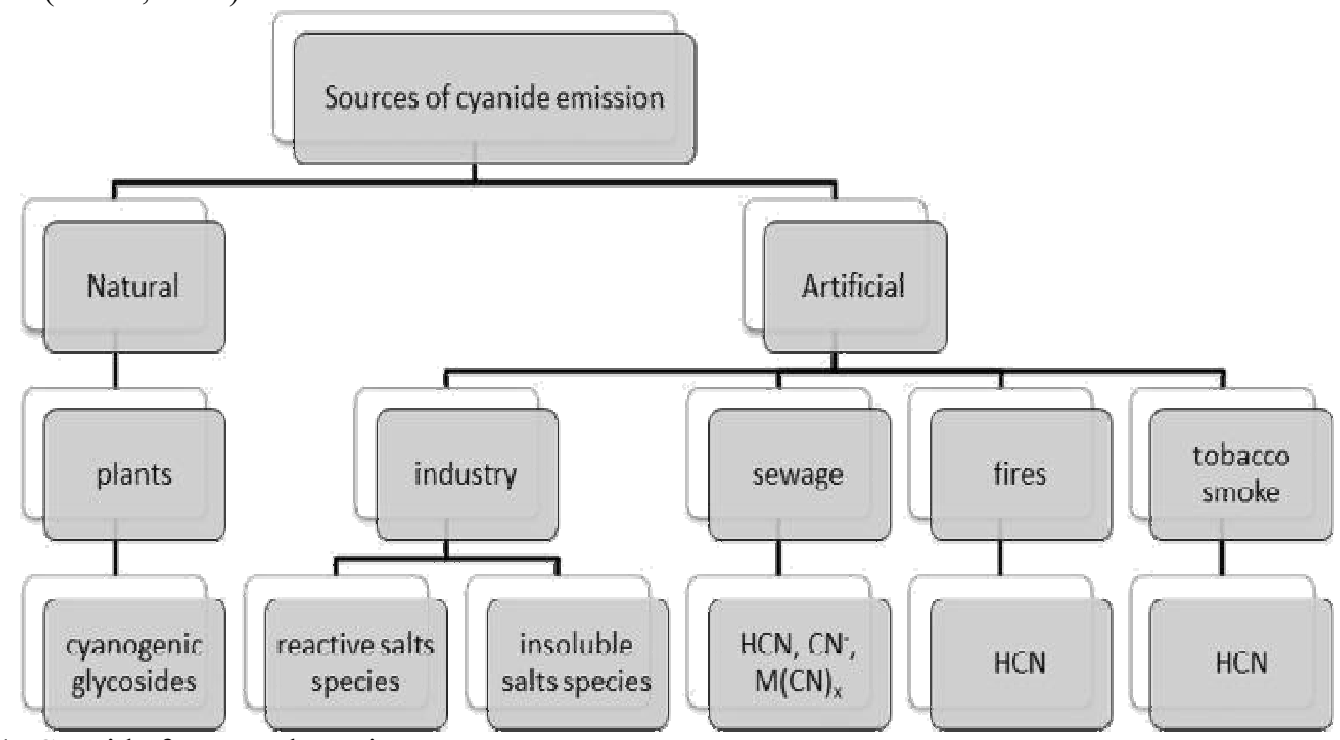

Figure 1: Cyanide forms and species.

Source: (Jaszczak et al., 2017).

\subsubsection{Risk Factors}

Plant and environmental factors: It is reported that, poisoning is most likely to occur when the cyanide content of the material is high and it is eaten quickly. Plants with a cyanide potential of more than $200 \mathrm{mg} \mathrm{HCN} / \mathrm{kg}$ plant dry matter are potentially toxic (Radostits et al., 2007). As much of available literature shows, high soil content of nitrogen and low phosphorus is favorable for high cyanide content in plant grown there (Vadlamudi, 2000). 
The risk of poisoning to ruminants decreases as forages mature. Moreover, leaf blades are higher risk than leaf sheaths or stems, upper leaves are higher risk than older leaves, and seed heads are considered low risk. However, drying plants decreases the cyanogenic potential over time so hay is rarely hazardous if adequately cured. Ensiling plants will significantly reduce the cyanogenic glycoside content (Arnold et al., 2014).

Relevant environmental factors include crushing, wilting, freezing, high environmental temperatures, herbicide treatment, water stress, cool moist growing conditions, nitrate fertilization, low soil sulfur (decreases detoxification of cyanogenic glycosides to thiocyanates with in plants), insect attack, and various plant diseases (Rhian, 2012). Any physical damage to plant tissue such as freezing (frost), macerating (rumination), cutting and drying, allows plant enzymes to come in close contact with and resulting in more hydrolysis to release more free HCN (Nicholson, 2007).

Animal factors: The rate of conversion of the glycoside to $\mathrm{HCN}$ in the rumen also affects the toxicity of the feed (Majak, 1992). Radostits et al. (2007) described that greatest danger exists in the following circumstances: when hungry animals allowed access to dense plant growths (1), cattle or sheep may break out of dry, summer pastures into fields of young, lush, immature sorghum or Sudan grass and gorge on it (2), traveling, recently introduced or other animals unaccustomed to local plants; animals accustomed to the plants and the poison can tolerate increasing doses with experience (3). Higher $\mathrm{pH}$ increases the rate of conversion of cyanogenic glycoside to HCN and thereby greaten the risk (4). This non-enzymatic pathway is pH-dependent. Water drunk after animals have eaten cyanogenic plants enhances the hydrolysis of the glycosides (5). Conversely, ruminants that are on high energy grain rations where the rumen is more acidic $(\mathrm{pH} 4-6)$ have a slower release of $\mathrm{HCN}$ than if they were fed a grass, hay, or alfalfa diet (Majak et al., 1990; Knight and Walter, 2002).

Therefore, high ruminal and abomasal $\mathrm{pH}$ increase the severity of toxicity. However, if the $\mathrm{pH}$ is lower than 5.0, the enzymes that separate the glycosides from the cyano become denatured and toxicity does not occur (Vetter, 2000). Ruminants are more susceptible to poisoning by cyanogenic plants, which release hydrogen cyanide than horses and pigs due to more efficient hydrolysis of the cyanogenic glycosides (Clarke et al., 1981). Monogastric animals with low stomach $\mathrm{pH}$ are also somewhat less susceptible to cyanogenic glycoside poisoning. However, these factors do not guarantee immunity from poisoning (Rhian, 2012).

Lethal dose: It is shown that, the lethal dosage of $\mathrm{HCN}$ in most animal species is in range of $2 \mathrm{mg} / \mathrm{kg}$ to 2.5 $\mathrm{mg} / \mathrm{kg}$ (Clarke et al., 1981; Knight and Walter, 2002; Schneider, 2012). The minimum lethal dose of HCN is about $2 \mathrm{mg} / \mathrm{kg} \mathrm{BW}$ for cattle and sheep when taken in the form of a glycoside (Radostits et al., 2007). Within the group of ruminants, goats appear to be the most susceptible to cyanide (Patel et al., 2014). Based on the available data the following intake $\mathrm{mg}$ hydrogen cyanide $(\mathrm{HCN})$ equivalents $/ \mathrm{kg} \mathrm{b.w}$. per day) seems to be tolerated by the following animal species: pigs $(2.9 \mathrm{mg} / \mathrm{kg}$ per day), poultry $(2.8 \mathrm{mg} / \mathrm{kg}$ per day), ruminants (on the basis of goats studies $(0.25 \mathrm{mg} / \mathrm{kg}$ per day) and horses $(0.4 \mathrm{mg} / \mathrm{kg}$ per day), respectively (EFSA, 2007).

Table 2: Level of HCN in forages (dry matter basis) and potential effect on animals.

\section{Sr. No HCN/kg feed(ppm) Effects of HCN on animals}

\begin{tabular}{lll}
\hline 1 & $0-500$ & Generally safe \\
2 & $600-1000$ & Potentially toxic
\end{tabular}

$3>1000 \quad$ Dangerous to cattle and usually cause death

Source :(Kraig et al., 2012).

\subsection{Pathogenesis}

Toxicity can result from accidental, improper, or malicious use or exposure. However, in livestock species, the most frequent cause of acute and chronic cyanide poisoning is ingestion of plants that either constitutively contains cyanogenic glycosides or is induced to produce cyanogenic glycosides and cyanolipids as a protective response to environmental conditions (plant cyanogenesis) (Rhian, 2012). In normal cases the glycosides occur in vacuoles in plants tissue, whereas the enzymes are found in the cytosol. When the edible parts of the plants are macerated, the catabolic intracellular enzyme B-glucosidase can be released, coming into contact with the glycosides. This enzyme hydrolyzes the cyanogenic glycosides to produce hydrogen cyanide and glucose and ketones or benzaldehyde. The hydrogen cyanide is the major toxic compound causing the toxic effects (Speijers, 1993). 


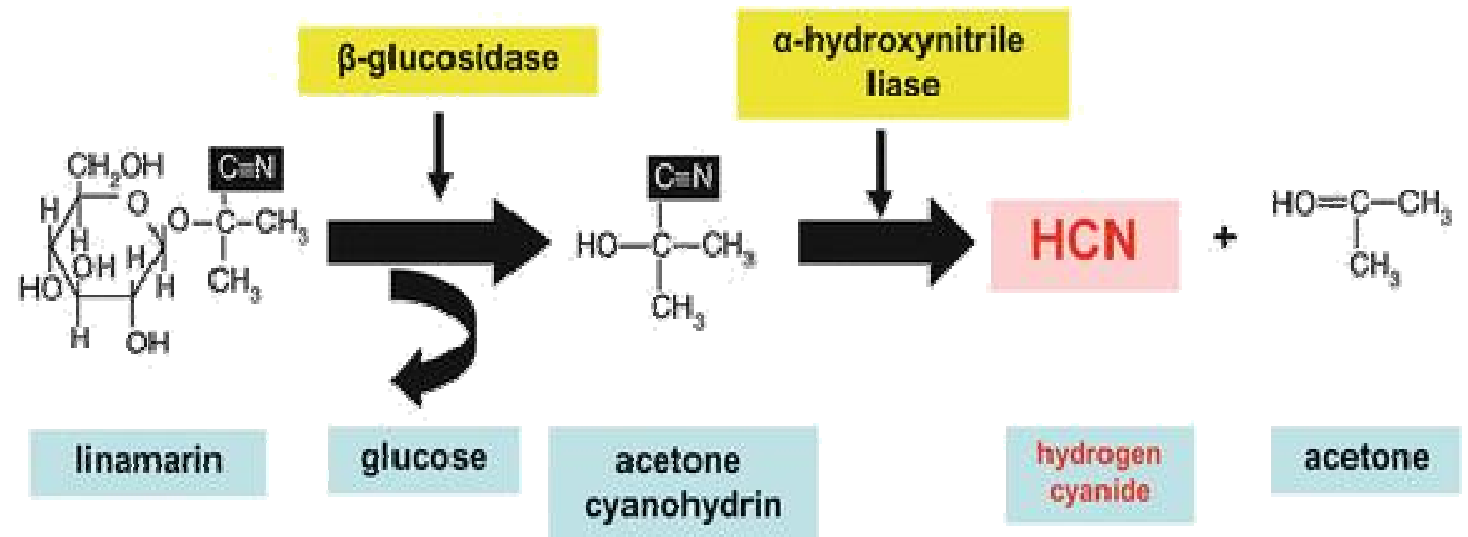

Figure 2: Release of HCN from cyanogenic plant (e.g Manihot esculenta, Cassava).

Source :( Gomez and Stuefer, 2006).

\subsubsection{Acute Intoxication}

It is reported that, ruminants are more likely to be poisoned by plant origin cyanide than other animals because rumen microorganisms readily release cyanide from the glycoside (Gupta, 2012). Cyanide is highly lethal because it diffuses into tissues and binds to target sites within seconds (Shepherd and Velez, 2008). Moreover, toxicokinetics review of cyanide shows intravenous and inhaled exposures produce more rapid onset of signs and symptoms because these routes provide fast diffusion and direct distribution to target organs via the bloodstream (Nelson, 2006). However, less rapid progression of symptoms with survival times of several hours has also been reported, particularly in cases of exposure by ingestion (Borron et al., 2004).

If the cyanide is taken to the body, it's rapidly absorbed and circulated, then it's merged with methemoglobin and forms cyanomethemoglobin. It is reported that the primary mechanism of cyanide excretion is formation of thiocyanate within the liver. Rhodanese catalyzes the conversion of cyanide to thiocyanate, and thiocyanate is then excreted via the kidneys (Shepherd and Velez, 2008). This mechanism is overwhelmed by high doses of cyanide in acute poisoning or in patients with decreased kidney function (Nelson, 2006).

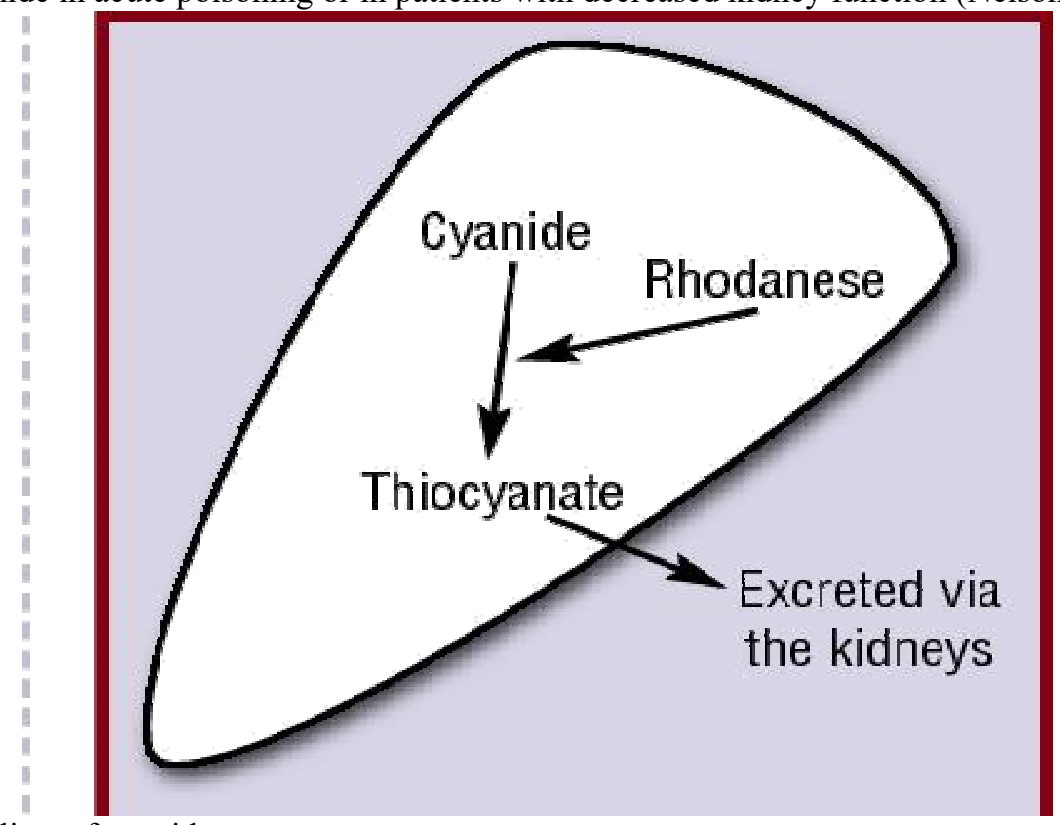

Figure 3: Metabolism of cyanide.

Source :( Hamel, 2011).

The enzyme rhodanese catalyzes conversion of cyanide to the nontoxic thiocyanate in the liver, and the thiocyanate is then excreted via the kidneys (Hamel, 2011). Cyanide ion has a high affinity for ferric (trivalent) iron in the cytochrome oxidase system and combines with it. Cytochrome c oxidase ( $\mathrm{CcO}$ or complex IV) is the last enzyme (terminal oxidase) in the respiratory electron transport chain located also in the bacterial mitochondrial membrane. This causes blocking of electron transport and molecular oxygen transfer from oxyhemoglobin to tissues, resulting into reversible cellular hypoxia or histotoxic anoxia Nicholson (2007) thus, tissues with higher oxygen demands suffer greatly in cyanide poisoning. This process is reversible. 


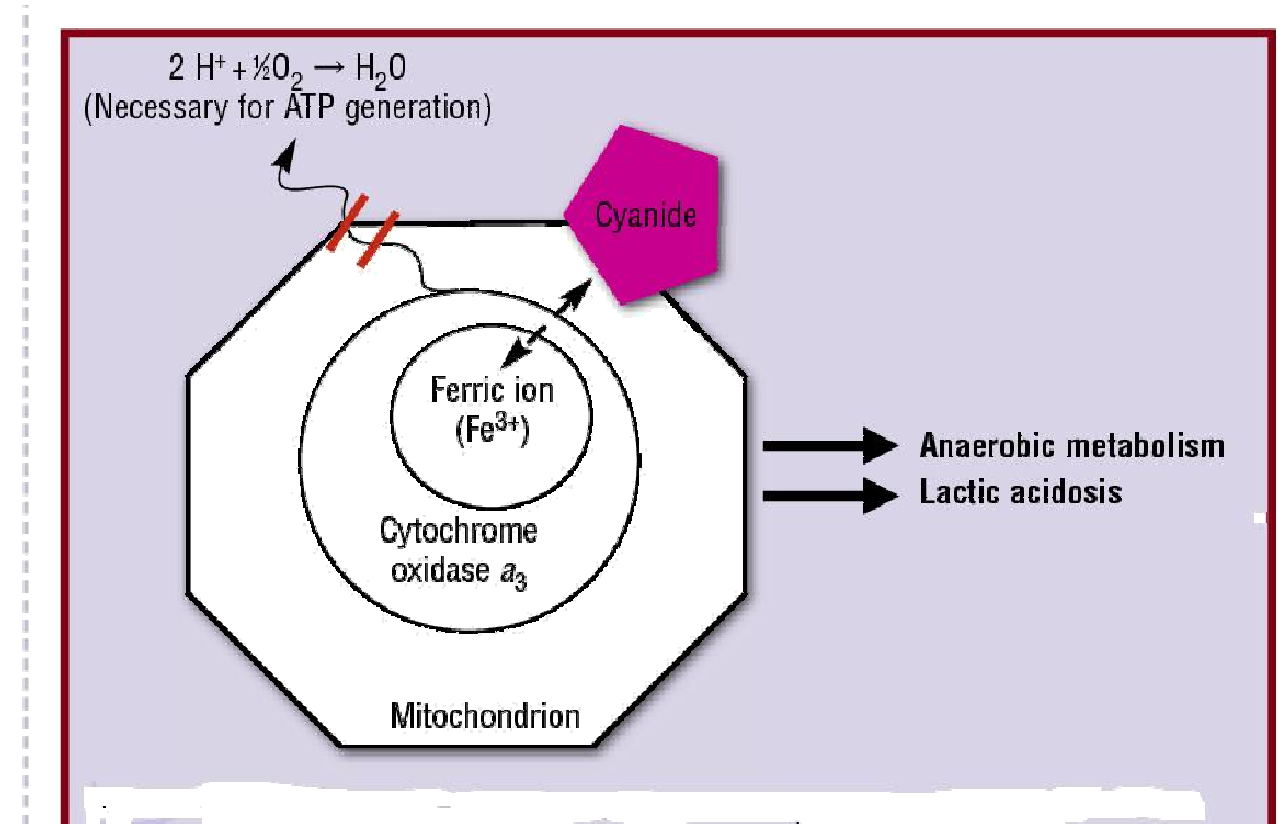

Figure 4: Effect of cyanide on cellular respiration.

Source :( Hamel, 2011).

Cyanide reversibly binds to the ferric ion in cytochrome oxidase a3 within the mitochondria, effectively halting cellular respiration by blocking the reduction of oxygen to water (Hamel, 2011). In bovines, this large transmembrane protein complex contains two hemes (iron sites) i.e. cytochrome a (haeme a) and cytochrome a3 (haeme a3), and two copper centers, the $\mathrm{CuA}$ and $\mathrm{CuB}$ centers (Tsukihara et al., 1995).

Cytochrome a3 is the site for oxygen (O2) binding when it is in the reduced state and acts as the $\mathrm{O} 2$ reduction site in conjunction with $\mathrm{CuB}$ which is located nearby. Fully reduced $\mathrm{CcO}$ has unusually high affinity to $\mathrm{CN}$ - and not $\mathrm{HCN}$. Cyanide (CN-) bound form undergoes a fairly large conformational change in the $\mathrm{O} 2$ reduction site Yoshikawa et al. (2012); hence, blocks electron transport resulting in decreased oxidative metabolism and oxygen utilization even in the presence of adequate oxygen stores. The decreased $\mathrm{O} 2$ causes oxygen tensions to rise in peripheral tissues resulting in decreased unloading gradient for oxyhemoglobin and thus, oxyhemoglobin are carried in the venous blood (ATSDR, 2006). The patient cannot use caloric oxygen and cellular respiration stops immediately. As a result of this process, death occurs due to histotoxic anoxia (Akgül et al., 2013). This process is reversible.

\subsubsection{Chronic poisoning}

Doses which do not produce clinical effects appear to be well-tolerated. The tolerance appears to increase with experience. Chronic, low-level cyanide/cyanogenic glycoside exposure (often in combination with low dietary sulfur or sulfur amino acid intake) is associated with neuropathy syndromes in horses and ruminants (Rhian, 2012). In case of goats receiving low dose of cyanide showed lower body weight gains and a decrease in plasma T3 concentrations. Behavioral changes have also been reported in goats following sub-lethal cyanide intoxication with delayed signs of toxicity (Soto-Blanco et al., 2005).

Cyanides ingested in small amounts, however, are known to be goitrogenic through the effects of thiocyanate, e.g. pregnant ewes grazing on star grass (Cynodonn lemfuensis) develop goiter due partly to a low iodine intake and partly to the cyanide intake. Their lambs may also be goitrous and have skeletal deformities. Furthermore, leucomyelomalacia (cystitis ataxia syndrome) in ruminants has been reported by (Radostits et al., 2007). Generally, developmental defects were observed in cows associated with chronic cyanide toxicity (Seaman et al., 1981).

\subsection{Clinical Signs}

If large quantities of cyanide are absorbed rapidly enough, the body's detoxification mechanisms are overwhelmed and the animal soon dies. Affected animals rarely survive more than 1-2 hours after consuming lethal quantities of cyanogenic plants and usually die within 5-15 minutes of developing clinical signs of poisoning (Arnold et al., 2014). Generally, signs quickly develop in acute cyanide intoxication including hyperventilation, decreased blood pressure, hypoxemia-induced convulsions, coma, shock, respiratory failure and death. The progression after the onset of convulsion is rapid and animal has characteristic bright cheery red colored mucous membrane (Plumlee, 2004).

In the more common, acute, cases the animals show depression, staggering, gross muscle tremor and 
dyspnea. There may be hyperesthesia and lacrimation. The muscle tremor is evident first in the head and neck, but soon spreads to involve the rest of the body; the animal becomes weak and goes down. The pulse is small, weak and rapid, and may be irregular. There is dilatation of the pupils, nystagmus, with congestion and cyanosis of the mucosae in the terminal stages (Radostits et al., 2007).

Many articles report, the blood, both arterial and venous, becomes cherry red from accumulated oxyhemoglobin (Lewis, 2000; Bingham et al., 2001). The skin may also be a bright pink color from the high concentration of oxyhemoglobin in the venous return (HSDB, 2005). When the intracellular cyanide concentration is less than $0.2 \mu \mathrm{g} / \mathrm{ml}$, symptoms of poisoning do not occur. Ruminants may exhibit signs within minutes to less an hour after commencing ingestion of toxic plant material which includes apprehension, pronounced polypnea then dyspnea, because initially there is stimulation of chemoreceptors in the carotid body and respiratory centers (Nicholson, 2007).

The goats suffered with acute cyanide toxicosis were found depressed, tachycardic, and had marked jugular pulses. The goats that died collapsed shortly before death (Tegzes et al., 2003). Sub-lethal cyanide intoxication in goats resulted in transient clinical signs which included depression and lethargy, mild hyperpnoea and hyperthermia, arrhythmias, abundant salivation, vocalizations, expiratory dyspnoea, jerky movements and head pressing; and convulsion later on in some animals (Soto-Blanco et al., 2005). When the cyanide level is between 0.5 and $1 \mu \mathrm{g} / \mathrm{ml}$ hyperemia of the skin and tachycardia and between $1-2.5 \mu \mathrm{g} / \mathrm{ml}$ unconsciousness and excitement are seen. At the levels above, patients will easily enter coma and die. A symptom of poisoning occurs due to hypoxia (Gurnsey et al., 1977).

In chronic poisoning, patients may have incoordination, ataxia, head shaking and pawning in the posterior extremities. Decrease of productivity, difficulty on conception and abortion can be also seen in such patients (Arnold et al., 2014). Urinary incontinence, loss of hair due to scalding, and incoordination of the hind limbs occur in horses, cattle, and sheep grazing Sorghum sudanense (Sudan or hybrid Sudan grass). In sheep, the syndrome includes weakness, ataxia, head shaking, fetlock knuckling, recumbency, and opisthotonos. As result of fetal central nervous damage by cyanide, cows grazing sorghum may rarely produce offspring with arthrogryposis probably as result of fetal central nervous system damage by cyanide (Radostits et al., 2007).

\subsection{Necropsy Findings}

It is reported that, venous blood is classically described as being "bright cherry red"; however, this color rapidly fades after death or if the blood is exposed to the atmosphere. Whole blood clotting may be slow or not occur. Mucous membranes may also be pink initially, and then become cyanotic after respiration ceases. The rumen may be distended with gas; in some cases, the odor of "bitter almonds" may be detected after opening (Rhian, 2012). Subendocardial and subepicardial petecchial and ecchymotic hemorrhages typical of an agonal death may be present. A "bitter almond" or "cherry coke" odor from stomach contents may be detectable. Venous blood may not be bright red in animals dead several hours (Nicholson, 2007). Cyanotic mucosa, dark muscles, lung edema and hemorrhages were observed at postmortem of died cattle (Nobrega et al., 2006).

\subsection{Diagnosis}

Cyanide is rapidly lost from animal tissues unless collected within a few hours of death and promptly frozen. It is reported that for collection and transmit, samples must be placed in a container that can be tightly sealed, samples must be frozen, and they must be transported in cold chain (Nobrega et al., 2006). According to Morocco (2005) cyanide analysis must be performed on suspected feeds and plants or cattle's rumen content for the diagnosis. Suitable specimens for more sophisticated testing include the suspected food source, rumen/stomach contents, and samples of the rumen gas cap, heparinized whole blood, liver, and muscle (Rhian, 2012).

Furthermore the most important in the diagnosis of cyanide poisoning is to identify plants in the area accessible to the animals and determine if they are likely to contain cyanogenic glycosides (Arnold et al., 2014). To be satisfactory, liver samples must be taken within 4 hours of death and muscle tissue within 20 hours. Based on literature data, the most commonly used methods of cyanide ion determination are spectrophotometric techniques as well as gas and liquid chromatography (Bolstad-Johnson et al., 2000). A level of HCN of 0.63 $\mathrm{J} . \mathrm{lg} / \mathrm{mL}$ in muscle justifies a diagnosis of poisoning. Serum and rumen fluid of poisoned cattle have been assayed using GC-MS (Gas Chromatography Mass Spectrometry (Meiser et al., 2000).

Low concentrations of cyanide in tissues are indicative of intoxication. Severe metabolic acidosis (elevated blood lactate or reduced blood $\mathrm{pH}$ ) together with an increased anionic gap are indicative. Whole, heparinized blood samples collected in airtight containers with no air space (submitted immediately or frozen) can also be analyzed for cyanohaemoglobin or cyanide (Patel et al., 2014). As there is an affinity of cyanide to bind to erythrocytes, the spleen may contain elevated cyanide concentrations (Shlosberg and Booth, 2006). Alkaline picrate treated filter paper strips can be used for testing plant materials and fresh rumen contents by modified Guignard test (Burrows and Tyrl, 2013). This is a sensitive and qualitative test popularly known as Picrate Paper 
test. Commercial field kits are also available.

\subsection{Differential Diagnosis}

The challenges in recognizing acute cyanide poisoning can be originated from nonspecific early symptoms of toxicity such as dizziness, weakness, diaphoresis, hyperpnea and labored breathing. Patients including these symptoms can be misdiagnosed with nitrate poisoning, organophosphorus poisoning and sulphur poisoning (Gracia and Shepherd, 2004). According to Nicholson(2007) and Radostits et al.(2007) differential diagnosis of cyanide poisoning in ruminants may include acute toxicoses caused by nitrate-nitrites, urea-ammonia, ipomeanol, bluegreen algae, electrical shock or lightning strike, acute pulmonary oedema, anaphylaxis and others.

According to Kutay et al. (2017) there are some distinguishing characteristics to eliminate cyanide poisoning from other events. Prussic acid causes the animal's blood to turn a bright cherry red but, the blood of animals affected with nitrate poisoning will be chocolate brown. Providing sodium nitrite to animals suffering from nitrate poisoning rather than prussic acid poisoning could make these animals worse. Findings such as bitter almond odour and early formation of death attendance are characteristic to cyanide poisoning in the necropsy (Arnold and Gaskill, 2014).

\subsection{Treatments}

Cyanide toxicity is effectively treated by any means that prevents access of cyanide $(\mathrm{CN})$ to issues, allowing for rhodanase action and a means to supply sulfur for thiocyanate formation. The treatment must promote the production of blood methemaglobin $(\mathrm{Hb}-\mathrm{Fe} 3+)$. The antidotal effect is based on the readiness with which free $\mathrm{CN}^{-}$combines with the $\mathrm{Hb}-\mathrm{Fe} 3+$ to form cyanomethemoglobin $(\mathrm{Hb}-\mathrm{Fe} 3+-\mathrm{CN})(\mathrm{John}, 1980)$. In human only 2 cyanide antidotes, hydroxocobalamin and a component of the cyanide antidote kit, sodium thiosulfate, have been proposed for empiric therapy in cyanide poisoning (Sauer and Keim, 2001).

Treatment must be initiated on emergency basis. Oral dosing with sodium thiosulfate into the rumen and/or stomach has been suggested well because the reaction between thiosulfate and cyanide can also occur nonenzymatically, and this may reduce any ongoing production of cyanide in the rumen/stomach environments (Rhian, 2012). The antidote of choice in most of animals is combination of sodium nitrite and sodium thiosulfate (also known as sodium hyposulfite or hypo). The sodium nitrite act as methemoglobin forming agent and is administered to form methemoglobin and bind cyanide as described below (figure. 5). Amyl nitrite is another methemoglobin forming agent used alone or with sodium nitrite. Sodium thiosulfate is administered in combination with the nitrites to clear cyanide by acting as a sulfhydryl donor. The unbound, extracellular cyanide binds with sulfur of thiosulfate to form the renally excreted thiocyanate (Patel et al., 2014).

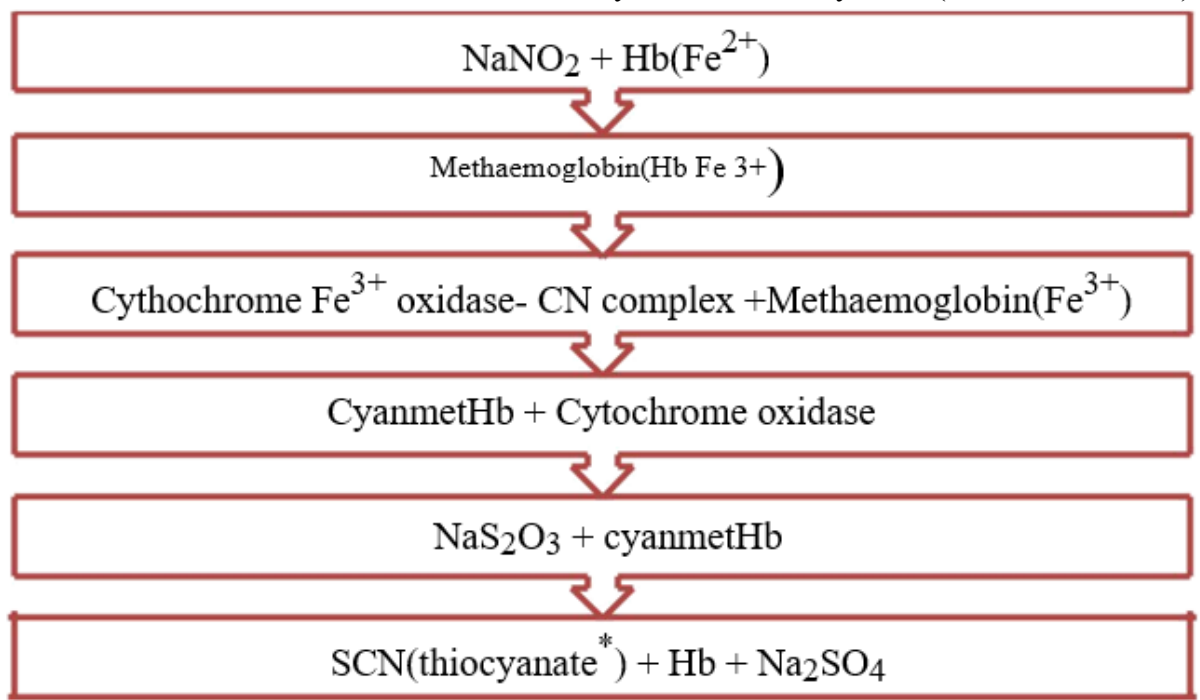

Figure 5: Biochemical mechanisim of reversal of the cyanide poisoning.

Source :( Garg, 2000).

Radostits et al. (2007) describe that the standard primary treatment is the IV injection of a mixture of sodium nitrite and sodium thiosulfate $(5 \mathrm{~g}$ sodium nitrite, $15 \mathrm{~g}$ sodium thiosulfate in $200 \mathrm{ml}$ water for cattle; $1 \mathrm{~g}$ sodium nitrite, $3 \mathrm{~g}$ sodium thiosulfate in $50 \mathrm{ml}$ water for sheep. In all cases and in animals exposed but showing no signs, doses of $30 \mathrm{~g}$ of sodium thiosulfate are given orally to cattle and are repeated at hourly intervals. Nonspecific supportive treatment, including respiratory stimulants and artificial respiration are unlikely to have any effect on the course of the disease. Ruminants can be treated with thiosulfate alone using a 30-40\% solution 
intravenous at a dose of $25-50 \mathrm{~g} / 100 \mathrm{~kg}$ body weight (Nicholson, 2007). This is due to in the presence of a sulfur donor (e.g. thiosulfate) and a sulfur transferase enzyme (e.g. rhodanese); $80 \%$ of a dose of $\mathrm{CN}$ is metabolized to $\mathrm{SCN}^{-}$(Logue, 2010).

Rumenotomy can be conducted to transfer normal rumen content. Patient's rumen content should be removed and replaced with contents from a healthy animal (Borron, 2006). Hydroxocobalamin (vitamin $\mathrm{B}_{12 \mathrm{a}}$ ) is also used as a cyanide antidote. However, for treatment of cyanide intoxication of ruminants, doses of sodium nitrite should be smaller than those recommended for other animals because ruminants are more susceptible to the toxic effects of sodium nitrite. Treatment with any choice of regimen should be repeated because of further liberation of HCN. Moreover Sulfenegen which recently developed antidote that has been proved 100 per cent effective in reducing blood cyanide level (Patel et al., 2014).

Hydroxocobalamin detoxifies cyanide by binding to it and forming cyanocobalamin (i.e., another decoy receptor approach), which is then excreted in urine. It has the advantages that it is relatively well tolerated, does not compromise blood oxygen-carrying capacity, and does not produce hypotension. The suggested dosage is 70 $\mathrm{mg} / \mathrm{kg}$, infused IV over $15 \mathrm{~min}$, repeated as necessary. Hyperbaric oxygen therapy (100\% oxygen breathed intermittently at a pressure $>1$ atmosphere absolute) causes an above-normal partial pressure of oxygen $\left(\mathrm{PO}_{2}\right)$ in arterial blood and markedly increases the amount of oxygen dissolved in plasma (Rhian, 2012). Oral therapy with glucose, molasses, or glyceraldehyde may provide a benefit. These products act as slow antagonists by tying up free HCN into cyanhydrin. However, due to the slow nature of this detoxification, they should not be used as a primary treatment (Burrows and Tyrl, 2013).

\subsection{Control and Prevention}

Hungry cattle and sheep should not be allowed access to toxic plants, especially cultivated Sorghum spp. when they are chronically drought-stressed, immature, wilted, frostbitten, or growing rapidly after a stage of retarded growth. For most Sorghum cultivars, stock should be allowed to graze them, or be fed green chop made from them, only after the plants exceed $75 \mathrm{~cm}$ in height (Radostits et al., 2007). Plants must not be grazed during drought periods when growth is severely reduced or the plant is wilted or twisted. Animals must have been provided sufficient feed, like hay, so they will not be hungry when they enter fresh pastures (Kutay et al., 2017). Moreover this will reduce the amount of prussic acid consumed and allow more time for the animal to detoxify low levels of $\mathrm{HCN}$. If high cyanide is suspected at the forages, cattle must not have been fed as green chop (Nobrega et al., 2006).

Preventive measures suggested to livestock owners include: (i) Ensure animal graze only old sorghum and avoid new growth, (ii) Medium strength nitrate fertilizers should be used with manure which has high phosphate level (Lorgue et al., 1996), (iii) Animals should be restricted from grazing sorghums during early re-growth after the plants have been cut, drought, or frosted, (iv) Allowing sorghum forages to grow at least 2 feet high before allowing animals to graze them,(v) Hay making and ensilaging reduces the cyanide content, (vi) Hybrid varieties (sudan-grass) and selected forage sorghums that have been specifically developed for low cyanogenic glycoside content should be used as forage crops (Knight and Walter, 2002), (vii) The $\mathrm{pH}$ in the stomach plays a major role in the hydrolysis of the cyanogenic glycoside. Lowering the stomach $\mathrm{pH}$ by feed management and supplements reduces the risks from cyanogenic forage, and (viii) Sulphur supplements in salt can also be used to increase the rate of natural detoxification and resistance (Burrows and Tyrl, 2013).

\section{CONCLUSION AND RECOMMENDATIONS}

Based on the data presented in this review; it can be concluded that cyanide poisoning is one of the most important poisoning that can affect livestock. It is highly lethal and rapidly acting toxin to which ruminants are more susceptible. The risks of poisoning can be affected by level of cyanide in plant material that varies with environmental stressors to plants as well as stage of plant growth. The mechanism of cyanide toxicity is associated with inhibition of oxygen utilization by binding with ferric (trivalent) ion in cytochrome oxidase $a_{3}$ within mitochondria and resulting into histotoxic anoxia. As result of this, the clinical signs are the reflection of intracellular hypoxia, discoloration of mucosae, pronounced respiratory distress and neurological signs in general. Immediate diagnosis and treatments with sodium thiosulphate and sodium nitrite can be done in together with supportive therapy for early noticed cases. Since any stress condition to plants that retard their growth results increased level of cyanide in plants with cyanogenetic potential, avoiding of ruminants' access to drought stressed, immature, wilted, frostbitten or rapidly growing plants, and in parallel with providing of grain or hay before turning to pasture is sound control method of hydrocyanic acid (HCN) poisoning in ruminants.

Therefore, based on above conclusion, the following recommendations are forwarded:

$>$ The rapid administration of sodium thiosulphate alone or in combination with sodium nitrite intravenously (IV) to early noticed should be done to reduce losses of livestock.

$>$ Lowering of rumen $\mathrm{pH}$ by feed supplement and management should be applied to prevent risk of cyanide poisoning from potentially dangerous forages. 
> Clinically useful diagnostic methods should be developed to confirm diagnosis and in order to make results available in reasonable time.

$>$ Awareness creation to livestock owners on prussic acid poisoning and its prevention measures should be conducted.

$>$ Agricultural industries should continue to produce forage crops with low cyanogenic potential is recommended.

$>$ Research should be conducted on prussic acid poisoning in ruminants to propose framework on economic impact, accurate diagnostic techniques and on strategic implementation of prevention measures.

\section{REFERENCES}

Akgül, G., Mecitoğlu, Z. and Şentürk, S.(2013). Sığırlarda respiratorik distreseveas feksiyeyolaçanönemlizhirlenmeler. Uludağ Üniv. Journal Faculty of Veterinary Medicine, 32(1):47-52.

Arnold, M. and Gaskill, C. (2014). Cyanide poisoning in ruminants. Agriculture and Natural Resources Publications, ELBS and Baillaire, Tindall, pp. 175-178

Arnold, M., Gaskill, C., Smith, S.R. and Lacefield, G.D. (2014). Cyanide Poisoning in Ruminants. Availableat:http://uknowledge.uky.edu/anr_reports/168. Accessed May, 2018.

ATSDR (Agency for Toxic Substances and Disease Registry). (2006). Toxicological profile for cyanide. Public Health Service, U.S. Department of Health and Human Services, Atlanta, GA. Available online at: http:// www. atsdr. cdc. gov/ toxprofiles /tp8. html. Accesed May, 2018.

Bingham, E., Cohrssen, B. and Powell, C.H. (2001). Patty's Toxicology. Fifth edition.

John Wiley and Sonseds, New York, N.Y. pp. 4:1384.

Bolstad-Johnson, D.M., Burgess, J.L., Crutchfield, C.D., Storment, S., Gerkin, R., Wilson, J.R. (2000). Characterization of firefighter exposures during fire American Industrial Hygiene Association Journal, 61:636-641.

Borowitz, J.L., Kanthasamy, A.G.and Isom, G.E. (1992). Toxic Dynamics of Cyanide. In: Chemical Warfare Agents. Ed. Somani, S.M., Academic Press, San Diego, pp. 209-236.

Borron, S.W., Stonerook, M. and Reid, F. (2006). Efficacy of hydroxocobalamin for the treatment of acute cyanide poisoning in adult beagle dogs. Clinical Toxicology, 44(1):5-15.

Borron, S., Megarbane, B. and Baud, F. (2004). Hydroxocobalamin is an effective antidote in severe acute cyanide poisoning in man. International Journal of Toxicology, 23:399-400.

Burrows, G. and Tyrl, R. (2013).Cycadaceae, Toxic Plants of North America, Second Edition, pp.402-409.

Charlie, S. and Greg, L. (September, 2012). Cyanide Poisoning. North Dakota State University Veterinary Diagnostic Laboratory at (701) 231-8307.

Clarke, M., Harvey, D. and Humphreys, D. (1981). Veterinary Toxicology, Second edition. ELBS and Bailliers, Tindal. Pp.175-178.

Dalefield, R.R., 2000. Rapid method for the detection of cyanide gas release from plant material using CYANTES MO paper. Veterinary and human toxicology, 42(6):356-357.

Davies, D.W., Kadar, D., Steward, D.J. and Munro, I.R. (1975). A sudden death associated with the use of sodium nitroprusside for induction of hypotension during anaesthesia. Canadian Anaesthetists' Society Journal, 22(5):547-552.

EFSA (European Food Safety Authority). (2007). Opinion of the Scientific Panel on Contaminants in the Food Chain on a request from the Commission related to cyanogenic compounds as undesirable substances in animal feed. The European Food Safety Authority Journal, 434: 1- 67. 14.

EPA (U.S. Environmental Protection Agency). (2010). Toxicological review of hydrogen cyanide and cyanide salts, EPA/635/R-08/016F, Washington, DC, pp.1-67.

Francisco, I. and Pinotti, M. (2000). Cyanogenic glycosides in plants. Brazilian Archives of Biology and Technology, 43(5): 487-492.

Jaszczak, E., Polkowska, Ż., Narkowicz., S. and Namieśnik, J. (2017). Cyanides in the environment analysis problems and challenges. Environmental Science and Pollution Research, 24(19): 15929-15948.

Gark, S. (2004). Veterinary Toxicology. First edition. CBC Publishers, India pp.87-91. Garg, S.K. (2000). Veterinary toxicology. Cyanogenetic Plants CBS publishers,

DaryaGani, New Delhi, India. pp. 87-91.

Gracia, R. and Shepherd, G. (2004). Cyanide poisoning and its treatment.

Pharmacotherapy 24: 1358-1365.

Gomez, S. and Stuefer, J.F. (2006). Members only: induced systemic resistance to herbivory in a clonal plant network. Oecologia, 147(3):461-468.

Gupta, R. (2012). Veterinary toxicology: basic and clinical principles. New York, Academic press. Pp.873-875.

Gurnsey, M.P., Jones, W.T., Merrall, M. and Reid, C.S.W. (1977).Cyanide poisoning in cattle: two unusual cases. New Zealand Veterinary Journal, 25(5): 128-130. 
Hall, A., Dart.R. and Bogdan, G. (2007).Sodium thiosulfate or hydroxocobalamin for the empiric treatment of cyanide poisoning? Annals of emergency medicine, 49(6): 806-813.

Hamel, J. (2011). A review of acute cyanide poisoning with a treatment update. Critical care nurse, 31(1): 72-82.

Haque, M. and Bradbury, J. (2002). Total cyanide determination of plants and foods using the picrate and acid hydrolysis methods. Food chemistry, 77(1):107-114.

HSDB (Hazardous Substances Data Bank). (2005). Hydrogen Cyanide (74-90 8). Toxicology ingestion of California Holly (Heteromelesar butifolia). Journal of Veterinary Diagnostic Investigation, 15: 478-480.

JECFA (Joint FAO/WHO Expert Committee on Food Additives). (1993). Cyanogenic Glycosides. In: Toxicological evaluation of certain food additives and naturally occurring toxicants. Geneva, 39th Meeting of the JEFCA (WHO Food Additives Series 30). World Health Organization, Geneva.

John, O. and Frederick, W. (1980). Cyanides and their toxicity: A literature review, Veterinary Quarterly, 2:2, 104-114.

Jaszczak, E., Polkowska, Ż., Narkowicz, S. and Namieśnik, J. (2017). Cyanides in the environment analysis problems and challenges. Environmental Science and Pollution Research, 24(19): 15929-15948.

Knight, A.P. and Walter, R. G. (2002). Plants Causing Sudden Death. In: A Guide to Plant Poisoning of Animals in North America, International Veterinary Information Service (www.ivis.org), Ithaca, New York, USA, pp. 5.

Kraig, R., Dave, M., Dale, B. and John, H. (2012). Prussic Acid Poisoning. Kansas State University. Accessed May, 2018. Available at:https://www.bookstore.ksre.ksu.ed u/pubs/MF3040.

Kutay, Y., Banu, D., Remzi, G., M. and Erman,O. (2017). Cyanide Poisoning in Cattle. Dairy and Veterinary Science Journal, 1(4): 55.

Kuyucak, N. and Akcil, A. (2013).Cyanide and removal options from effluents in gold mining and metallurgical processes. Miner England. 50:13-29.

Logue, B.A., Hinkens, D.M., Baskin, S.I., Rockwood, G.A. (2010). The analysis of cyanide and its breakdown products in biological samples. Critical Reviews in Analytical Chemistry, 40:122-147.

Lorgue, G., Lechenet, J. and Riviere, A. (1996). In: Clinical Veterinary Toxicology.

Blackwell Science Ltd. UK, pp. 136-137.

Majak, W. (1992). Metabolism and absorption of toxic glycosides by ruminants. Journal of Range Management, pp.67-71.

Meiser, H., Hagedorn, H.W. and Schulz, R. (2000). Development of a method for determination of cyanide concentrations in serum and rumen fluid of cattle. American Journal of Veterinary Research, 61(6): 658664.

Morocco, A.P. (2005). Cyanides. Critical care clinics, 21(4): pp.691-705.

Mudder, T.I., Botz, M. (2000). A global perspective of cyanide mineral resources forum. United Nations Environment Programme. p.5

Nelson, L. (2006). Acute cyanide toxicity. mechanisms and manifestations. Journal of Emergency Nurse. 32(4 suppl):8-11.

Newhouse, K. and Chiu, N. (2016). Toxicological review of hydrogen cyanide and cyanide salts. Washington, DC: EPA. Available at: http://www.epa.gov/iris/toxreviews/0060tr. Accessed May, 2018.

Nicholson, S. S. (2007). Cyanogenic plants. In: Veterinary Toxicology: Basic and Clinical Principles (Edited. Gupta, R. C.). Academic Press, USA, pp. 873- 875.

Nobrega, J., Riet-Correa, F., Medeiros, R. and Dantas, A. (2006). Poisoning by of sodium nitroprusside for induction of hypotension during anesthesie. Canadian Anaesthetists' Society Journal, 22: 547, (1975).

Patel. H., Singh, R., Mody, S., Modi, C. and Kamani, S. (2014). Cyanide Poisoning In Animals. Department of Pharmacology and Toxicology College of Veterinary Science and Animal Husbandry, an International eJournal, Vol. 3: 202-216.

Plumlee, K. H. (2004). Plants: cyanogenic glycoside. In: Clinical Veterinary Toxicology, Mosby Inc., Missouri pp. 391- 392.

Radostits, O. M., Gay, C. C., Hinchcliff, K. W. and Constable, P. D. (2007). Veterinary Medicine: A Textbook of the diseases of cattle, sheep, goats, pigs, and horses. Tenth Edition, Saunders Elsevier, London. pp. 18521855 .

Radostits. O.M., Gay. C.C., Blood. D.C. and Hinchcliff. K.W.( 2003). Veterinary Medicine. A textbook of the disease of cattle, sheep, pigs, goats and horses. Book Power Puublication.1632-1636.

Rhian, B. (2012). Overview of Cyanide poisoning. In: The Merck's Veterinary Manual Availableat:https://www.msdvetmanual.com/toxicology/cyanidepoisoning/overvi ew-of-cyanide poisoning. Accessed May, 2018.

Sauer, S.W. and Keim, M.E. (2001). Hydroxocobalamin: improved public health readiness for cyanide disasters. Annals of Emergency Medicine, 37:635-641.

Schneider, N. R. (2012). Overview of Cyanide poisoning. In: The Merck's Veterinary Manual Online. 
Availableat:http://www.merckmanuals.com/vet/toxicology/cyanid epoisoning/ overview of cyanide poisoning. Accessed May, 2018.

Shepherd, G. and Velez, L. (2008). Role of hydroxocobalaminin acute cyanide poisoning. Annals Pharmacotherapy, 42(5):661-669.

Shlosberg, A. and Booth, L. (2006). Veterinary and clinical treatment of vertebrate pesticide poisoning. A technical review, Landcare Research, Lincoln, NZ, pp. 29-33.

Smith, O.B. (1992). A review of ruminant responses to cassava-based diets. Cassava as livestock feed in Africa.

Soto-Blanco, B., Stegelmeier, B. L. and Górniak, S. L. (2005). Clinical and pathological effects of short-term cyanide repeated dosing to goats. Journal of Applied Toxicology, 25: 445-450.

Speijers, G. (1993). Cyanogenic glycosides. WHO Food Additives Series, 30: pp.299-337.

Sykes, A.H. (1981). Early studies on the toxicology of cyanide. Cyanide in Biology, pp.1-9.

TOXNET (Toxicology Data Network). (2013). National Library of Medicine. Available at http://toxnet.nlm.nih.gov. Accessed May, 2018.

Tegzes, J.H., Puschner, B. and Melton, L.A. (2003). Cyanide toxicosis in goats after ingestion of California Holly (Heteromelesar butifolia). Journal of Veterinary Diagnostic Investigation, 15(5): 478-480.

Tewe, O. O. (1992). Detoxication of cassava products and effects of residual toxins on consuming animals. In: Proceedings FAO Expert Consultation, Colombia, pp.81-97.

Tsukihara, T., Aoyama, H., Yamashita, E., Tomizaki, T., Yamaguchi, H., Shinzawa-Itoh, K., Nakashima, R., Yaono, R. and Yoshikawa, S. (1995). Structures of metal sites of oxidized bovine heart cytochrome c oxidase. Animal Science. 269 (5227): 1069- 1074.

Vadlamudi, V. P. (2000). Cyanogenetic Plants. In: Veterinary Toxicology (Edited. S.K.

Garg), First edition, CBS Publishers, New Delhi, pp. 87-91.

Vennesland, B.,Conn, E.,Knowles, C., Westley, J. and Wissing, F. (1981), Cyanide in Biology, Academic Press, and London p. 517.

Vetter, J. (2000)."Plant cyanogenic glycosides". Toxicon, 38(1):11-36.

Vickery, P., Wheeler, J.and Mulcahy, C. (1987). Factors affecting the hydrogen cyanide potential of white clover (Trifolium repens). Australian Journal of Agricultural Research.3:1053-1059.

Vough, L. (1978). Preventing prussic acid poisoning of livestock.p.35

Yoshikawa, S., Muramoto, K.,Shinzawa-Itoh, K. and Mochizuki, M. (2012). Structural studies on bovine heart cytochrome c oxidase. Biochimicaet Biophysica Acta, 18: 579-589. 